\title{
Pattern Of Changes In Plasma Lipids And Lipoprotein Cholesterol Levels Through Normal Pregnancy And Peurperum In Ile-Ife, Nigeria.
}

\author{
Salawu A A*, Ajose O A**, Adegoke O A**, Adedosu A N***, \\ Adeyemi A B ****, Aboderin $\mathrm{A} \mathrm{O} * * * * *$. \\ * Department of Chemical Pathology, OAUTHC. \\ ** Department of Chemical Pathology, OAU. \\ *** Department of Med. Micro. And Parasitology, OAUTHC. \\ **** Department of Obst. and Gynae., OAU. \\ ***** Department of Med. Micro. And Parasitology, OAU.
}

\begin{abstract}
A longitudinal studies was carried out in OAUTHC Ile-Ife to determine the pattern of changes in plasma lipids and lipoprotein cholesterol levels in 145 normal pregnant patients.

Patients were bled serially first at initial visit at the centre at late first trimester or early second trimester, then twenty four to twenty six weeks of gestation; thirty six to thirty eight weeks of gestation and at end of peurperium.Plasma levels of $T C, T G, H D L-C$ were assayed in the plasmaand $L D L-C$ levels were derived using fried wald formula at each level.
\end{abstract}

The mean $\pm S D$ of $T C, T G, H D L-C$ and $L D L-C$ showed a significant increase with increasing gestational age and reduction at the end of peurperium. The mean differences demonstrated a larger percentage increase in the second trimester as compared with the late third trimester in TC and TG.The TG showed the largest percentage increase.However the $H D L-C$ showed a persistent increase throughout gestation though mild.All parameters reduce to pre-pregnancy level at puerperium.

In conclusion,the plasma lipids and lipoprotein cholesterol increase throughout pregnancy. All parameters reduce to normal level in the puerperium.

\section{Introduction:}

During pregnancy, maternal metabolism must satisfy the demands of the developing fetus in addition to the energy requirements of the mother ${ }^{1}$. The growth of the foetus is a complex process guided by an interplay between mother, placenta, and fetus ${ }^{2}$. This depends on nutrients such as glucose, lipids, and amino acids ${ }^{2}$.

The anabolic phase of early pregnancy result in an increased deposition of fat in maternal adipose tissue. Late pregnancy is characterised by the release of free fatty acids from adipocytes and is enhanced by both relative insulin resistance and stimulation of hormone-sensitive lipase by placental hormones ${ }^{3}$. Normal pregnancy is also associated with high concentrations of oestrogens which may contribute to the rise in plasma lipids especially in the late half of pregnancy ${ }^{4}$. There is a profound effect of dietary habits on the lipid metabolism in pregnancy.

Pregnancy represent a state of stress requiring extra energy source. Lipids serve as alternate energy supply for pregnancy sustainability ${ }^{6}$. Thus high plasma level of lipids and lipoprotein cholesterol in this physiologic state is normal and has since been established in various studies in the past ${ }^{7-11}$. Although most of these studies are cross-sectional studies, very few longitudinal studies alluded to this ${ }^{4,12,13}$. This changes in maternal metabolism occur to satisfy the nutritional demands of the fetus ${ }^{1,14}$. The present study is a longitudinal study undertaken in Ile-Ife, a sub-urban town in south western Nigeria, Africa, to study the pattern of changes and the mean differences in individual parameters as pregnancy progresses.

\section{Materials And Methods;}

One hundred and forty five healthy pregnant women attending antenatal clinic (ANC) in OAUTHC were recruited consecutively at various gestational ages(GA) of 1 st trimester and early 2 nd trimester. They were followed through 2 nd trimester, 3rd trimester to $6 / 52$ postpertum. They were seen and bled serially; first at points of recruitment, then $24-26$ weeks of GA , $34-36$ weeks of GA and 6/52 postpartum. Subjects with diseases and complications such as hypertension, hyprothyrodism, gestational DM, renal failure, nephoritic syndrome, and obesity were excluded from this study.

Blood specimens was obtained by venipuncture under sterile condition into lithium heparinized tubes. Blood samples were centrifuged within 10minutes of collection, using a bench-top centrifuge at 3000rpm for 5 minutes and the plasma separated into plain allequat bottles and stored at $-20^{\circ} \mathrm{C}$ until laboratory analyses . 
Concentrations of total cholesterol (TC), and triglycerides (TG) were analysed enzymatically using commercially available reagents kit (RANDOX) $)^{15,16}$. The HDL-C was determined from the supernatant after other lipoprotein cholesterol fractions were separated by precipitation techniques using sodium phosphotungstate and magnesium chloride ${ }^{17}$. The concentration of low density lipoprotein cholesterol (LDL-C) was calculated using the Friedewald equation for participants with $\mathrm{TG}$ level $<4.5 \mathrm{mmol} / \mathrm{L}^{18}$. Accuracy was monitored by adding RANDOX commercial quality control sera(low, normal, high) to all batch analyses.

\section{Statistical Analysis:}

Data entry and statistical analysis utilising the IBM SPSS 20 package. Descriptive statistics expressing mean as mean \pm standard deviation (mean $\pm \mathrm{SD}$ ) and Student's t-test to test for statistical significance.

\section{Results:}

Plasma lipids and lipoprotein cholesterol were determined from 145 healthy pregnant women from first or early second trimester, through all trimesters till peurperium. The subjects were aged between $17-40 \mathrm{yrs}$ with mean age of $26.06 \pm 5.07$. Their weight ranges between $40-80 \mathrm{~kg}$ at recruitment with a mean $\pm \mathrm{SD}$ of $56.80 \pm 7.11$; Height ranged between $1.32-1.75 \mathrm{~m}$ with mean \pm SD $0.53 \pm 0.07$.

$42.1 \%$ were recruited in the first trmester while $57.9 \%$ were recruitd in their early second trimester. $33.1 \%$ were nulliparous, $33.1 \%$ were para 1 and $33.8 \%$ are multiparous. About $93.1 \%$ of the subjects are the indiginous Yorubas; $51 \%$ were petty traders, $20.7 \%$ were artisants, $13.1 \%$ were students/apprentices, $7.6 \%$ were full house wives, $6.7 \%$ were civil servants, and .7\% were farmers.

Tables 1,2,3 shows mean \pm SD of the lipid profile of 1 st and 2nd timesters, 2nd and 3rd trmesters, 3rd and 6/52 postpartum respectively with difference mean values at $p$-value 0.000 .

Table 1: Shows mean \pm SD and the mean difference of lipid profile in 1st -2 nd Trimesters:

\begin{tabular}{|l|l|l|l|l|}
\hline & $\begin{array}{l}\text { 1st trimester(n=61) mean } \pm \\
\text { SD }\end{array}$ & $\begin{array}{l}\text { 2nd trimester(n=61) } \\
\text { mean } \pm \text { SD }\end{array}$ & Mean difference & $\mathrm{p}-$ value \\
\hline \hline TC & $3.92 \pm 1.08$ & $4.68 \pm 1.30$ & $0.75 \pm 0.33$ & 0.000 \\
\hline \hline TG & $0.98 \pm 0.23$ & $1.37 \pm 0.23$ & $0.40 \pm 0.18$ & 0.000 \\
\hline \hline HDLC & $0.96 \pm 0.24$ & $1.04 \pm 0.23$ & $0.08 \pm 0.04$ & 0.000 \\
\hline \hline LDLC & $2.96 \pm 0.89$ & $3.60 \pm 1.17$ & $0.64 \pm 0.38$ & 0.000 \\
\hline
\end{tabular}

Table 2: Shows mean \pm SD and the mean difference of lipid profile in 2nd - 3rd Trimesters:

\begin{tabular}{|l|l|l|l|l|}
\hline & $\begin{array}{l}\text { 2nd Trimester(n=145) } \\
\text { Mean } \pm \text { SD }\end{array}$ & $\begin{array}{l}\text { 3rd Trimester(n=145) } \\
\text { Mean } \pm \text { SD }\end{array}$ & $\begin{array}{l}\text { Mean difference } \\
\text { Mean } \pm \text { SD }\end{array}$ & $\begin{array}{l}\mathrm{p} \\
\text { value }\end{array}$ \\
\hline TC & $4.77 \pm 1.20$ & $5.37 \pm 1.23$ & $0.60 \pm 0.22$ & 0.000 \\
\hline TG & $1.34 \pm 0.29$ & $1.73 \pm 0.34$ & $0.04 \pm 0.15$ & 0.000 \\
\hline HDLC & $1.06 \pm 0.20$ & $1.15 \pm 0.20$ & $0.10 \pm 0.05$ & 0.000 \\
\hline LDLC & $3.70 \pm 1.07$ & $4.23 \pm 1.20$ & $0.52 \pm 0.30$ & 0.000 \\
\hline
\end{tabular}

Table 3 : Shows mean \pm SD and the mean difference of lipid profile in 3rd Trimester \& 6/52 postpartum:

\begin{tabular}{|l|l|l|l|l|}
\hline & $\begin{array}{l}\text { 3rd trimester(n=145) } \\
\text { mean } \pm \text { SD }\end{array}$ & $\begin{array}{l}\text { 6/52 postpartum(n=145) } \\
\text { mean } \pm \text { SD }\end{array}$ & Mean difference & $\mathrm{p}$ - value \\
\hline \hline TC & $5.37 \pm 1.36$ & $4.29 \pm 0.97$ & $1.08 \pm 0.58$ & 0.000 \\
\hline \hline TG & $1.73 \pm 0.34$ & $1.04 \pm 0.24$ & $0.70 \pm 0.22$ & 0.000 \\
\hline \hline HDLC & $1.15 \pm 0.20$ & $1.03 \pm 0.22$ & $0.13 \pm 0.15$ & 0.000 \\
\hline \hline LDLC & $4.23 \pm 1.2$ & $3.26 \pm 0.83$ & $0.96 \pm 0.59$ & 0.000 \\
\hline
\end{tabular}

\section{Discussion:}

All lipids and lipoprotein cholesterol fractions increase with increasing age of pregnancy. This result is consistent with most previous studies ${ }^{4,12,13}$. This increment is however attributed to the great impact exacted by reduced activity of lipoprotein lipase with the concomittant variation in female sex hormones particularly estrogen and progesterone levels on lipid metabolism during pregnancy ${ }^{3,4}$.

Plasma TC shows a higher percentage increase in the second trimester than that of third trimester as indicated by the mean differences. This might not be unconnected to the use of cholesterol for increase steriodogenesis and cell and organ differentiations at this period.

Plasma TG showed a markedly reduced increment in the third trimester over the second, definitely because of increase energy expenditure of the third trimester. However, HDL-C showed slight percentage increase in the third trimester than the second. This is actually suporting removal of cholesterol to sites of steriodogenesis and also reducing arteriogenesity ${ }^{19}$. 
The lipids and lipoprotein cholesterol fractions reduced to their normal reference value 6/52 postpartum. The percentage of reduction of TG is greater than that of TC probably because TG is use for energy as well as in milk production.

\section{Conclusion}

There is significant progressive increase in plasma lipids and lipoprotein Cholesterol levels in pregnancy and reduced to normal levels postpartum. The increment is however more in the late second trimester than in the late third trimester.TG showed a higher percentage increase than TC. HDL-C showed a small but persistent increase throughout the course of pregnancy.

\section{Acknowledgement:}

The Authors express their profound gratitude to the Department of Obst. and Gynae., OAUTHC. Special thanks to Doctors Adeyemi AS , Akinboro AO ,Oloyede WT ,Kareem RA of LAUTECH University.

\section{Reference:}

[1]. Winkler K, Wetzka B, Hoffman M, Friedrich I, Kinner M, Baumstark M, et al. low-density lipoprotein (LDL) sub fractions during pregnancy; accumulation of buoyant LDL with advancing gestation. J Clin Endocrinol Metab. 2000;85:4543-50.

[2]. Langer O: Fetal macrosomia: etiologic factors. Clin Obstet Gynecol.2000;43: 283-297.

[3]. Wakatsuki A, Ikenoue N, Izumiya C, Okatani Y. Effects of estrogen and simvastatin on low-density lipoprotein subclass in hypercholesterolemic postmenopausal women. Obstet Gynecol. 1998;3:367-71.

[4]. Alvarez J, Montelongo A, Iglesias A. and Lasuncion M. Longitudinal study on lipoprotein profile, high density lipoprotein subclass, and postheparin lipases during gestation in women. J. Lipid Res. 1996; 37, 299-308.

[5]. Di Cianni G, Miccoli R, Volpe L, Lencioni C, Del Prato S. Intermediate metabolism in normal pregnancy and in gestational diabetes. Diab. Metab. Res. 2003;19:259-70.

[6]. Peter A. Mayes. Lipid Transport and Storage. In: Robert K. Murrary, Daryl K. Granner, Peter A. Mayes, Victor W. Rodwell, editors. Herpers Biochemistry. 24th ed. Appleton and Lange; 1996,pg 254-270.

[7]. Ola R, Adedeji O. O. Plasma lipids during first Trimester in Pregnant Nigeria Women. Nig. Qt. J. Hosp. Med. 1997;7:111-113.

[8]. Jarikre A.E, Ola R, Abbiyesu M.F, Oluwatowoju I.O. Cross-sectional study of plasma Triglyceride and Cholesterol levels in first and second trimesters of pregnancy in Lagos. Nig. J. Int. Med. 2000;3:1-3.

[9]. Ajose O.A, Fasubaa O.B, Thomas K.D, Bolodeoku J.O. Serum lipids and lipoprotein cholesterol inpregnant Nigerian Women. J. Clin. Sc. 2002;2:9-13.

[10]. Ojule A.C, Akani C.I, Opurum H.C. Plasma lipids during pregnancy in Women Port Harcourt,Nigeria. Nig. J. Med. 2005;14:155160.

[11]. Adegoke OA, Iyare EE, Gbenebitse SO. Fasting plasma glucose and cholesterol levels in pregnant Nigerian women. Niger Post Grad Med J. 2003;10:32-6.

[12]. Jarikre A.E, Ola R. Longitudinal study of plasma Triglycerides and cholesterol levels in 1st, 2nd, 3rd Trimesters of pregnancy in Nigerian women in Urban Lagos. Nig. J. of Clinic Practice. 2000;3:51-54.

[13]. Emeka E. Neboh, John K. Emeh, Uzo U. Aniebue, Ebele J. Ikekpeazu, Ignatius C. Maduka, Frank O. Ezeugwu. Relationship between lipid and lipoprotein metabolism in trimesters of pregnancy in Nigerian women: Is pregnancy a risk factor?J. Nat. Sci. Biol. Med. 2012 Jan-Jun; 3(1): 32-37.

[14]. Karl W, Birigt W, Michael M.H, Isolde F. Martina K, Manfred W. B, et al. Low density lipoprotein sub-fraction during pregnancy; Accumulation of buoyant LDL with advancing gestation. J. Clin Endocrinology Metab. 2000;85:4543-4550

[15]. Allain CC, Poon LS, Chan SG, Richmond W, Fu P. Enzymatic determination of total serum cholesterol. Clin Chem. 1974;20:470475.

[16]. Buccolo G. David H. Quantitative determination of serum triglycerides by use of enzymes. Clin. Chem. 1973;19:476-482.

[17]. Bachorik P.S, Alber J.J. Precipitation methods for quantification of lipoprotein. Methods Enzymol 1986;129:78-100.

[18]. Friedwald W.T, Levy R.J, Fredrickson D.S. Estimation of the concentration of Low Density Lipoprotein Cholesterol in plasma without use of preparative ultracentrifuge.Clin. Chem. 1972; 18: 499-502.

[19]. Arnold von Eckardstein, Jerzy-Roch Nofer, Gerd Assmann. High Density Lipoproteins and Arteriosclerosis: Role of Cholesterol Efflux and Reverse Cholesterol Transport. Arterioscler. Thromb. Vasc. Biol. 2001;21:13-27. 